Article

\title{
Oral Administration System Based on Meloxicam Nanocrystals: Decreased Dose Due to High Bioavailability Attenuates Risk of Gastrointestinal Side Effects
}

\author{
Noriaki Nagai *, Fumihiko Ogata ${ }^{(\mathbb{D})}$, Hiroko Otake and Naohito Kawasaki ${ }^{(D)}$ \\ Faculty of Pharmacy, Kindai University, 3-4-1 Kowakae, Higashi-Osaka, Osaka 577-8502, Japan; \\ ogata@phar.kindai.ac.jp (F.O.); hotake@phar.kindai.ac.jp (H.O.); kawasaki@phar.kindai.ac.jp (N.K.) \\ * Correspondence: nagai_n@phar.kindai.ac.jp; Tel.: +81-6-4307-3638
}

Received: 3 March 2020; Accepted: 27 March 2020; Published: 1 April 2020

check for updates

\begin{abstract}
Meloxicam (MLX) is widely applied as a therapy for rheumatoid arthritis (RA); however, it takes far too long to reach its peak plasma concentration for a quick onset effect, and gastrointestinal toxicity has been observed in RA patients taking it. To solve these problems, we designed MLX solid nanoparticles (MLX-NPs) by the bead mill method and used them to prepare new oral formulations. The particle size of the MLX-NPs was approximately 20-180 nm, and they remained in the nano-size range for 1 month. The tmax of MLX-NPs was shorter than that of traditional MLX dispersions (MLX-TDs), and the intestinal penetration of MLX-NPs was significantly higher in comparison with MLX-TDs $(P<0.05)$. Caveolae-dependent endocytosis (CavME), clathrin-dependent endocytosis (CME), and micropinocytosis (MP) were found to be related to the high intestinal penetration of MLX-NPs. The area under the plasma MLX concentration-time curve (AUC) for MLX-NPs was 5-fold higher than that for MLX-TDs $(P<0.05)$, and the AUC in rats administered $0.05 \mathrm{mg} / \mathrm{kg}$ MLX-NPs were similar to rats administered the therapeutic dose of $0.2 \mathrm{mg} / \mathrm{kg}$ MLX-TDs. In addition, the anti-inflammatory effect of the MLX-NPs was also significantly higher than that of MLX-TDs at the corresponding dose $(P<0.05)$, and the therapeutic effect of $0.2 \mathrm{mg} / \mathrm{kg}$ MLX-TDs and $0.05 \mathrm{mg} / \mathrm{kg}$ MLX-NPs in adjuvant-induced arthritis (AA) rats showed no difference. Furthermore, the gastrointestinal lesions in AA rats treated repetitively with $0.05 \mathrm{mg} / \mathrm{kg}$ MLX-NPs were fewer than in rats receiving $0.2 \mathrm{mg} / \mathrm{kg}$ MLX-TDs $(P<0.05)$. In conclusion, we demonstrate that MLX solid nanoparticles allow a quick onset of therapeutic effect and that three endocytosis pathways, CavME, $\mathrm{CME}$, and MP, are related to the high absorption of solid nanoparticles. In addition, we found that MLX solid nanoparticles make it possible to reduce the amount of orally administered drugs, and treatment with low doses of MLX-NPs allows RA therapy without intestinal ulcerogenic responses to MLX. These findings are useful for designing therapies for RA patients.
\end{abstract}

Keywords: meloxicam; nanocrystals; oral absorption; gastrointestinal lesion; drug delivery system

\section{Introduction}

Meloxicam (MLX) is categorized as a Class II drug in the Biopharmaceutical Classification System (BCS) [1] and is a selective inhibitor of cyclooxygenase-2. MLX is used in both human and veterinary medicines [2] and is widely applied for the relief of joint pain caused by rheumatoid arthritis (RA), osteoarthritis, and other chronic joint diseases [3]. Although gastrointestinal toxicity of MLX is observed in patients with RA, the rate and degree of onset are lower than with other non-steroidal anti-inflammatory drugs (NSAIDs). MLX is also a promising drug for the treatment of cancer and Alzheimer's disease [4]. Despite this attractive pharmacological profile, the peak plasma concentration 
of MLX is reached only 3-7 $\mathrm{h}$ following the administration of an oral suspension, and $5-6 \mathrm{~h}$ after the administration of traditional MLX tablets [5,6]. This is far too long for a quick onset effect.

The permeability of dissolved MLX is a relatively good, and the bioavailability (BA) is approximately $89 \%$ after dissolution [7]. However, it has low dissolution and low solubility (approximately $4.4 \mu \mathrm{g} / \mathrm{mL}$ at water [1]), and these factors limit the absorption rate of MLX, since the undissolved meloxicam is little absorption. Thus, the slow oral absorption due to low solubility causes the slow expression of the pharmaceutical effects of MLX. In therapy for patients with acute exacerbation of rheumatism and osteoarthritis, rapid onset of pharmaceutical effects is important, and thus the development of a fast dispersible dosage form of highly soluble MLX nanocrystals (solid nanoparticles) is highly anticipated. In addition, the half-life of MLX is low (approximately $20 \mathrm{~h}$ ) [8] in comparison with other NSAIDs $[9,10]$. Therefore, the development of a technique for controlled release is also important in the MLX category drugs, such as piroxicam and neloxicam.

Amorphous solid dispersion techniques [11], emulsification [12], nano-pulverization [13], and salt formation [14] have been studied as approaches to enhance the aqueous solubility of poorly soluble drugs by the many researchers. Nano-pulverization is one technique to prepare solid nanoparticles, and the reduction of particle size to the submicron range can lead to a higher BA and dissolution rate [15-17]. We also reported that the inclusion of 2-hydroxypropyl- $\beta$-cyclodextrin $(\mathrm{HP} \beta C D)$ with nanoparticle preparations increases in solid nanoparticles prepared by the bead mill method, as well as improving permeability through the cornea [18], skin [19,20], and small intestine [21] in rats and rabbits. These previous studies suggest that the method based on the bead mill with the addition of cyclodextrin is an effective and simple technique for improving the oral absorption and dissolution behavior of drugs. In addition, it is possible that a dose reduction following the enhancement of BA may lead to less direct irritation to the gastrointestinal area, and may attenuate the onset of gastrointestinal toxicity of NSAIDs.

In this study, we designed MLX nanocrystals (solid nanoparticles) for oral administration (MLX-NPs) and studied the mechanism of their transintestinal penetration. Moreover, we demonstrate the effect of an oral administration system based on MLX solid nanoparticles on the pharmacokinetics and onset of gastrointestinal side effects, and the therapeutic effectiveness of MLX-NPs for inflammation using model RA rats.

\section{Materials and Methods}

\subsection{Reagents and Animals}

All reagents used were of the highest purity commercially available. The caveolae-dependent endocytosis (CavME) inhibitor nystatin was obtained from Sigma-Aldrich Japan (Tokyo, Japan). MLX (4-hydroxy-2-methyl-N-(5-methyl-2-thiazoly)-2H-1,2-benzo-thiazine-3-carboxamide-1,1 dioxide), HEPES, phagocytosis inhibitor cytochalasin D, and Bayol F were purchased from Wako Pure Chemical Industries, Ltd. (Osaka, Japan). HP $\beta C D$ was provided by Nihon Shokuhin Kako Co., Ltd. (Tokyo, Japan). Methylcellulose (MC) and heat-killed Mycobacterium butyricum were obtained from Nihon Shokuhin Kako Co., Ltd. (Tokyo, Japan) and Difco (Detroit, MI, USA), respectively. Streptomycin, penicillin, non-essential amino acid solution, L-glutamine, Dulbecco's modified Eagle's medium, and heat-inactivated fetal bovine serum were obtained from GIBCO (Tokyo, Japan). The Protein Assay Kit was purchased from Bio-Rad (Tokyo, Japan). The clathrin-dependent endocytosis (CME) inhibitor dynasore and micropinocytosis (MP) inhibitor rottlerin were provided by Nacalai Tesque (Kyoto, Japan). Transwell-Clear ${ }^{\mathrm{TM}}$ plates were obtained from Costar (Cambridge, MA, USA). Inertsil ${ }^{\circledR}$ ODS-3 column (diameter $2.1 \mathrm{~mm}$ ) was purchased from GL Science Co., Inc. (Tokyo, Japan). Male 6-week old Dark Agouti (DA) rats were obtained from Shimizu Laboratory Supplies Co. Ltd. (Kyoto, Japan). The experiments using rats were carried out in accordance with the Animals Guidelines of both the Kindai University (KAPS-30-003, 1 April 2018) and the Japanese Pharmacological Society. For the induction of RA (adjuvant-induced arthritis rat, AA rat), 50 microliters of Bayol F containing $10 \mathrm{mg} / \mathrm{mL}$ 
heat-killed Mycobacterium butyricum was injected into the plantar region of the right hind foot and tail (vehicle, $50 \mu \mathrm{L}$ of Bayol $\mathrm{F}$ was injected). The inflammation levels (paw edema) were evaluated by measuring paw volume by plethysmometry.

\subsection{Preparation of MLX Solid Nanoparticle-based Oral Formulations}

Nanoparticulation of MLX was carried out according to our previous reports [18-21]. HP $\beta C D$, MC, and MLX powder were added into $2 \mathrm{~mL}$ tubes containing $2 \mathrm{~g}$ of $0.1 \mathrm{~mm}$-zirconia beads and dispersed in purified water. The mixtures were milled 30 times at $5500 \mathrm{rpm}$ for $30 \mathrm{~s}$ at $4{ }^{\circ} \mathrm{C}$ by Micro Smash MS-100R (TOMY SEIKO Co., Ltd., Tokyo, Japan). The milled dispersions were filtered to remove the $0.1 \mathrm{~mm}$-zirconia beads, and the filtrates dispersions were used as MLX-NPs. Traditional MLX dispersions (MLX-TDs), used as the control, were prepared by the addition of HP $\beta C D, M C$, and MLX powder into purified water $(\mathrm{pH}=7)$. The prepared MLX-TDs and MLX-NPs were used to evaluate transintestinal penetration, BA, side effects, and therapeutic effects in this study. The compositions of meloxicam formulations prepared in this study were as follows: $0.5 \%$ meloxicam, $5 \% \mathrm{HP} \beta C D$, $0.5 \% \mathrm{MC}$. The formulations were diluted to $0.05 \mathrm{mg} / \mathrm{mL}$ and $0.2 \mathrm{mg} / \mathrm{mL}$ by using solution water containing $5 \% \mathrm{HP} \beta \mathrm{CD}$ and $0.5 \% \mathrm{MC}$, and used in each experiment. In the in vitro experiment using Caco- 2 cell and rat intestine, the $0.2 \mathrm{mg} / \mathrm{mL}$ meloxicam was used, and the $0.05 \mathrm{mg} / \mathrm{mL}$ and $0.2 \mathrm{mg} / \mathrm{mL}$ meloxicam formulations were used in $0.05 \mathrm{mg} / \mathrm{kg}$ and $0.2 \mathrm{mg} / \mathrm{kg}$ administration, respectively, in the in vivo study using rats.

\subsection{General Characteristics of MLX Formulations}

The particle frequency, nanoparticle-number, atomic force microscope (AFM) image, zeta potential, crystal form, concentration, and solubility were measured as general characteristics in this study. The particle frequency and nanoparticle-number of MLX-NPs were determined using NANOSIGHT LM10 (QuantumDesign Japan, Tokyo, Japan). The measurement time, wavelength, and viscosity were set at $60 \mathrm{~s}, 405 \mathrm{~nm}$, and $1.27 \mathrm{mPa} \cdot \mathrm{s}$, respectively. The particle frequency of MLX-TDs and MLX-NPs was also measured by SALD-7100 (Shimadzu Corp., Kyoto, Japan). The AFM images were obtained using an SPM-9700 (Shimadzu Corp., Kyoto, Japan), and the images were created by combining height and phase images. A micro-electrophoresis zeta potential analyzer model 502 was used to measure the zeta potential (Nihon Rufuto Co., Ltd, Tokyo, Japan). The crystal form was analyzed by a powder X-ray diffraction (XRD) method using Mini Flex II (Rigaku Co., Tokyo, Japan) under the following conditions: Diffraction angles, $5^{\circ}$ to $90^{\circ}$; X-rays, $30 \mathrm{kV}$ and $15 \mathrm{~mA}$; scanning rate, $10 \%$ min. For these measurements of the crystal form, lyophilized MLX-NPs was used as the sample. The MLX concentration was determined by an HPLC method. An LC-20AT system (Shimadzu Corp., Kyoto, Japan) with an Inertsil ${ }^{\circledR}$ ODS-3 column was used with a mobile phase consisting of potassium dihydrogen phosphate/methanol/acetonitrile $(63 / 27 / 10, v / v / v \%)$ at a flow rate of $0.25 \mathrm{~mL} / \mathrm{min}$. The MLX peak was detected at 7 minutes at a wavelength of $254 \mathrm{~nm}$. In experiments to measure solubility, the MLX in solution and the MLX nanoparticles were separated by centrifugation at 100,000 g using an Optima ${ }^{\mathrm{TM}}$ MAX-XP Ultracentrifuge (Beckman coulter, Osaka, Japan). The collected nanoparticles were dissolved in methanol. The MLX contents of the solutions and methanol-dissolved nanoparticles were measured by the HPLC method described above.

\subsection{Transepithelial Penetration of MLX using Caco-2 Cell Monolayers}

Ten percent heat-inactivated fetal bovine serum, $10 \mu \mathrm{g} / \mathrm{mL}$ streptomycin, $1000 \mathrm{IU} / \mathrm{mL}$ penicillin, 1\% L-glutamine, and 1\% non-essential amino acid were added into Dulbecco's modified Eagle's medium, and used to culture Caco- 2 cells. $9 \times 10^{4}$ Caco- 2 cells $/ \mathrm{cm}^{2}$ were seeded onto Transwell-Clear ${ }^{\mathrm{TM}}$, and cultured for 21 days. Transepithelial electrical resistance (TER) was measured using an epithelial Volt-Ohm meter (Millicell-ERS, EMD Millipore, Billerica, MA, USA). Caco-2 cell monolayers with TER values over $300 \Omega \cdot \mathrm{cm}^{2}$ were used in the transepithelial penetration experiments. The monolayers were set in the reaction chamber with HBSS/HEPES solution ( $\mathrm{pH} 7.4)$ in the basolateral side chamber and 
the MLX formulations on the apical side. Aliquots of the basolateral side solution were withdrawn at various times and replaced with the same volume of HBSS/HEPES solution. The MLX levels in the withdrawn aliquots were measured by the HPLC method described above. At the end of the experiment, the TER values were measured again to evaluate cell damage.

\subsection{Intestinal Penetration of MLX using Rat Jejunum and Ileum}

Eight-week-old rats were killed under deep isoflurane anesthesia, and the jejunum and ileum were carefully removed. Individual jejunum and ileum samples were set in methacrylate cells for intestinal penetration experiments. The donor and reservoir chambers were filled with MLX formulations and $10 \mathrm{mM}$ HEPES buffer (pH 7.4), respectively. Samples of the solutions in the reservoir chamber were withdrawn with time to investigate the penetration of MLX nanoparticles, and replaced with the same volume of $10 \mathrm{mM}$ HEPES buffer. The MLX levels were measured by the HPLC method described above. The experiments were carried out for $4 \mathrm{~h}$ under normal $\left(37^{\circ} \mathrm{C}\right)$ and low $\left(4{ }^{\circ} \mathrm{C}\right)$ temperature conditions. At the low temperature, all energy-dependent endocytosis was inhibited. In experiments using endocytosis inhibitors, the inhibitors were added to the reservoir chamber $20 \mathrm{~min}$ prior to the addition of the MLX formulation to the donor chamber. The inhibitors chosen were nystatin $(54 \mu \mathrm{M}$, CavME inhibitor) [22], dynasore (40 $\mu \mathrm{M}, \mathrm{CME}$ inhibitor) [23], rottlerin (2 $\mu \mathrm{M}, \mathrm{MP}$ inhibitor) [24], and cytochalasin $\mathrm{D}(10 \mu \mathrm{M}$, phagocytosis inhibitor) [22], and the trapezoidal rule up to the last measurement point $(4 \mathrm{~h})$ was used to analyze the area under the MLX concentration $(C)$-time curve $\left(A U C_{\text {penetration }}\right)$.

$$
A U C_{\text {penetration }}=\int_{0 \mathrm{~h}}^{4 \mathrm{~h}} C d \mathrm{t}
$$

\subsection{Absorption of Orally Administered MLX}

Cannulas were set into the right jugular veins of 8-week old rats under isoflurane anesthesia, and $200 \mu \mathrm{L}$ samples of blood were collected from right jugular veins via cannulas at various times to evaluate the changes in MLX levels after the oral administration of $0.05 \mathrm{mg} / \mathrm{kg}$ or $0.2 \mathrm{mg} / \mathrm{kg}$ MLX formulations. The collected venous blood from fasted rats was centrifuged at $800 \mathrm{~g}$ for $20 \mathrm{~min}$, and the MLX in the serum was extracted by the methanol, and measured by the HPLC method described above. The trapezoidal rule up to the last measurement point $(24 \mathrm{~h})$ was used to analyze the area under the MLX concentration-time curve $\left(A U C_{\text {plasma }}\right)$. The pharmacokinetics parameters were analyzed by Equations (2) and (3):

$$
\begin{gathered}
C_{\mathrm{MLX}}=C_{0} \times e^{-k_{\mathrm{e}} \times t} \\
C_{\mathrm{MLX}}=\frac{k_{\mathrm{a}} \times F \times D}{V_{\mathrm{d}}\left(k_{\mathrm{a}}-k_{\mathrm{e}}\right)}\left(e^{-k_{\mathrm{e}}(t-\tau)}-e^{-k_{\mathrm{a}}(t-\tau)}\right)
\end{gathered}
$$

The distribution volume $\left(V_{\mathrm{d}}\right)$ and elimination rate constant $\left(k_{\mathrm{e}}\right)$ was calculated using Equation (1) and data $(0-24 \mathrm{~h}, t)$ after a single injection $(0.3 \mathrm{ml})$ of MLX solution in DMSO $(0.04 \mathrm{mg} / \mathrm{kg})$ into the femoral vein, and levels of $64.5 \mathrm{~mL}$ and $2.45 \times 10^{-2} \cdot \mathrm{h}^{-1}$, respectively, were obtained. The apparent absorption rate constant $\left(k_{\mathrm{a}}\right)$ was estimated according to Equation (2). In the Equation, the $D, \tau, F$ show dose ( $\mu \mathrm{mol})$, lag time $(\mathrm{h})$, and the fraction of MLX absorbed, respectively.

\subsection{Content of MLX in Gastrointestinal Mucosa after the Oral Administration of MLX}

Fasted rats were orally administered $0.2 \mathrm{mg} / \mathrm{kg}$ MLX formulations, and killed under deep isoflurane anesthesia. The stomach, jejunum, and ileum were carefully excised, washed in saline, and the mucosa collected. MLX in the mucosal tissues was extracted in methanol, and measured by the HPLC method described above. 


\subsection{Lesions in the Gastrointestinal Mucosa after the Oral Administration of MLX}

AA rats, 14-42 days after the injection of Mycobacterium butyricum, were orally administered $0.2 \mathrm{mg} / \mathrm{kg}$ MLX formulations twice a day (7:00 and 19:00) for 1 month, and then killed under deep isoflurane anesthesia. The stomach, jejunum, and ileum were carefully excised, washed in saline, and fixed in $10 \%$ formalin, and digital images were obtained. The lesion areas in the stomach, jejunum, and ileum were analyzed using Image J (NIH) and expressed as the percentage of the total area.

\subsection{Anti-Inflammatory Effect of MLX Formulations in AA Rats}

The anti-inflammatory effect was evaluated by changes in paw edema of AA rats orally administered $0.05 \mathrm{mg} / \mathrm{kg}$ or $0.2 \mathrm{mg} / \mathrm{kg}$ MLX formulations. Paw edema of the right hind foot was measured by plethysmometry, and expressed as the difference in paw volume of rats injected with or without Mycobacterium butyricum. The trapezoidal rule up to the last measurement point (42 days) was used to analyze the area under the MLX concentration-time curve $\left(A U C_{\text {edema }}\right)$.

\subsection{Statistical Analysis}

Student's $t$-test and Dunnett's multiple comparisons were used. $P$ values less than 0.05 were considered significant. Data were represented as mean \pm standard error (S.E).

\section{Results and Discussion}

\subsection{Preparation of MLX Solid Nanoparticles for Oral Formulations}

Two basic methods, bottom-up (precipitation techniques) and top-down (disintegration processes), were used to obtain drug solid nanoparticles [25]. Solid nanoparticles are built up from drug molecules dissolved in an organic solvent in the precipitation techniques [26,27]; however, the organic solvent may cause toxicity when its residue remains in the final product, making the use of organic solvents undesirable. On the other hand, in top-down processes, the raw material is broken down until nanosized particles are produced. Among the top-down processes, wet bead milling and high-pressure homogenization are the two most widely used methods. In particular, wet bead milling produces particles in a smaller size range in comparison with the high-pressure homogenization processes [28]. Thus, wet bead milling is suitable to prepare solid nanoparticles, although increasing aggregation occurs during storage, reducing the dissolution rate and absorption. Therefore, the prevention of aggregation is important in the design of nanocrystal formulations [29,30]. In our previous studies, we showed that $\mathrm{HP} \beta C D$ attenuated the aggregation of nanocrystals, probably by coating the particles with HP $\beta C D$ [18-21]. In addition, we found that the presence of MC increased the mill efficiency of the bead mill method and prevented the separation of hydrophobic drugs and a polar solvent during the preparation of nanoparticles [18-21]. From these findings, we selected the bead milling method and used HPCD and MC to prepare MLX solid nanoparticles for this study. The particle size was decreased by the bead mill treatment (Figure S1) to yield MLX nanoparticles with a size in the range of $20 \mathrm{~nm}$ to $180 \mathrm{~nm}$ (Figure 1B-E) with a zeta potential of $-15.5 \mathrm{mV}$ (Figure 1G). Moreover, the solubility was enhanced by the bead mill treatment, with the solubility of MLX-NPs being 2.6-fold that of MLX-TDs (Figure 1F), and the XRD pattern of MLX was not changed by the bead mill treatment (Figure S2). It is known that the solubility of particles under $100 \mathrm{~nm}$ increases according to the Ostwald-Freundlich equation. As the particle size of MLX-NPs is $20 \mathrm{~nm}$ to $180 \mathrm{~nm}$ (Figure 1B-E), this may be the reason for the increase in solubility of MLX. In addition, our previous reports showed that the inclusion of HP $\beta C D$ also enhanced the solubility of solid nanoparticles that were smaller than $200 \mathrm{~nm}$ [18-21], and this may also be related to the increase in MLX solubility. On the other hand, the Ostwald-Freundlich equation indicates that the dispersion stability decreases with the increase in size distribution. In this study, the MLX particles were slightly aggregated 1 month after preparation, although the particle size remained in the nano-range (Figure 2B-E). No degradation was observed for 1 month, and zeta 
potential remained unchanged 1 month after preparation (Figure 2F,G). These results suggest that $\mathrm{HP} \beta C D$ and MC are useful additions for the preparation of MLX nanoparticles.

A
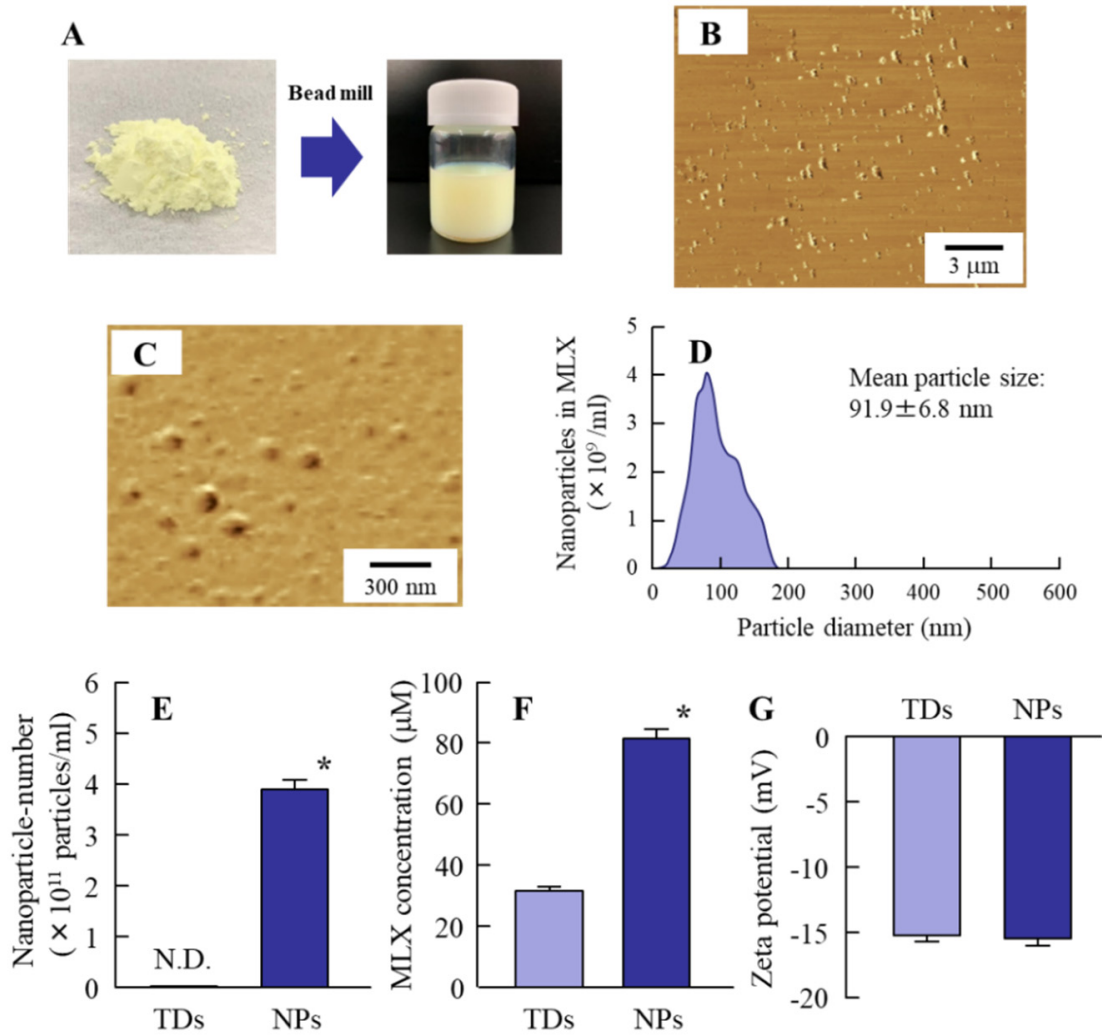

Figure 1. Characteristics of Meloxicam (MLX) after bead mill treatment. (A) Photographs of MLX before and after bead mill treatment. (B,C) Atomic force microscope (AFM) images of MLX-NPs in wide- (B) and narrow-fields (C). (D) Particle frequency of MLX solid nanoparticles (MLX-NPs) by NANOSIGHT LM10. (E-G) Nanoparticle number (E), solubility (F), and zeta potential (G) of MLX-NPs. $n=8 .{ }^{*} P<0.05$ vs. MLX-TDs for each category. MLX nanoparticles $\left(3.91 \times 10^{11}\right.$ particles $\left./ \mathrm{mL}\right)$ were obtained by bead mill treatment with a particle size of approximately $20-180 \mathrm{~nm}$. The solubility of MLX nanoparticles was 2.6-fold higher in comparison with MLX powder, and the zeta potential of MLX-NPs was $-15.5 \mathrm{mV}$. 
A

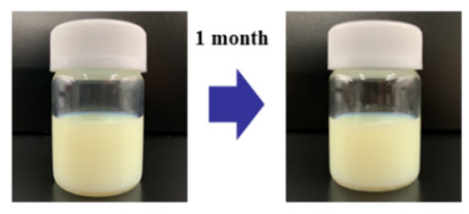

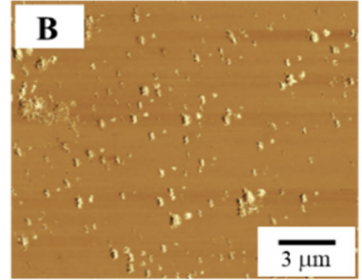

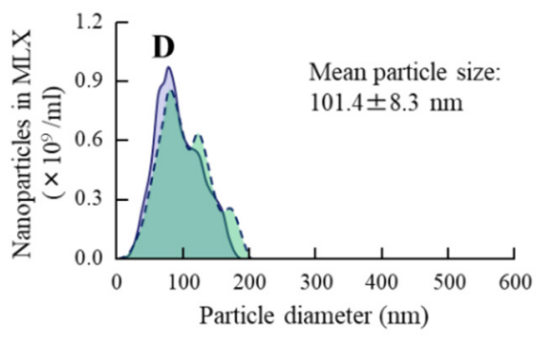

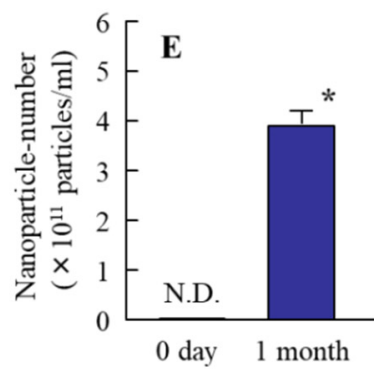

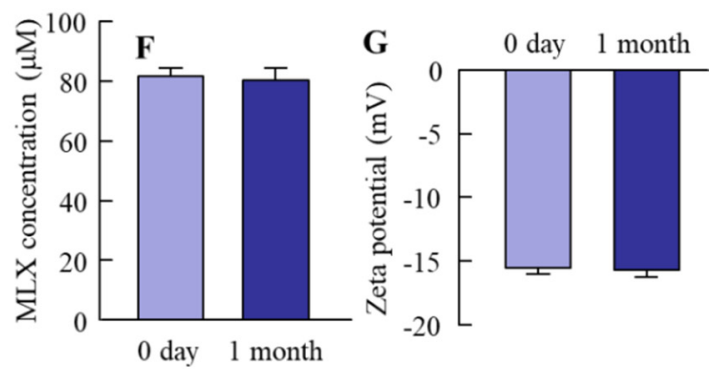

Figure 2. Stability of MLX-NPs 1 month after preparation. (A) Photographs of MLX-NPs at the time of preparation and 1 month after. (B,C), AFM images of MLX-NPs 1 month after preparation in wide(B) and narrow-fields (C). (D), particle frequency of MLX nanoparticles in MLX-NPs immediately (blue) and 1 month (green) after preparation. (E-G) Nanoparticle-number (E), solubility (F), and zeta potential (G) of MLX-NPs 1 month after the preparation. $n=8 .{ }^{*} P<0.05$ vs. 0 days for each category. Some agglutination of MLX particles was produced in the 110 to $150 \mathrm{~nm}$ and 150 to $190 \mathrm{~nm}$ ranges, however, the MLX particles remained in the nano-size range. There were no significant differences in the nanoparticle-number, solubility, or zeta potential between MLX-NPs immediately and 1 month after preparation.

\subsection{Relationships between Energy-Dependent Endocytosis and the Intestinal Penetration of MLX Solid Nanoparticles from Orally Administered Formulations}

Next, we investigated the mechanism of the intestinal penetration of MLX solid nanoparticles. In the clinic, the dose of MLX was $10 \mathrm{mg} /$ day ( $\max 15 \mathrm{mg} /$ day) in the adult, and the body weight in adults was approximately $50 \mathrm{~kg}$. Taken together, we selected a dose of $0.2 \mathrm{mg} / \mathrm{kg}(10 \mathrm{mg} / 50 \mathrm{~kg})$ in this study. Caco-2 expresses several markers characteristic of normal small intestinal villus cells, and Caco-2 cell monolayers are widely used to predict intestinal drug penetration [31,32]. The TER of Caco-2 cell monolayers reflects cell growth and the formulation of tight junctions [33-35]. In this study, we used Caco-2 cell monolayers with TER over $300 \Omega \cdot \mathrm{cm}^{2}$ (Figure S3A). Both the trans-epithelial penetration and intracellular uptake of MLX-NPs were significantly higher than those of MLX-TDs $(P<0.05$, Figure 3A,D). Moreover, MLX nanoparticles were detected on the basolateral side (Figure 3B,C, Figure S3B), and no difference was observed in cell stimulation between MLX-TDs and MLX-NPs (Figure 3E). It was known that the width of the intercellular space was approximately $40-100 \mathrm{~nm}$, and the particle size in MLX-NPs was 20-180 nm (Figure 1). These results show that the MXL nanoparticles in MXL-NPs can pass through Caco-2 cell monolayers in the solid-state (nanoparticles). 

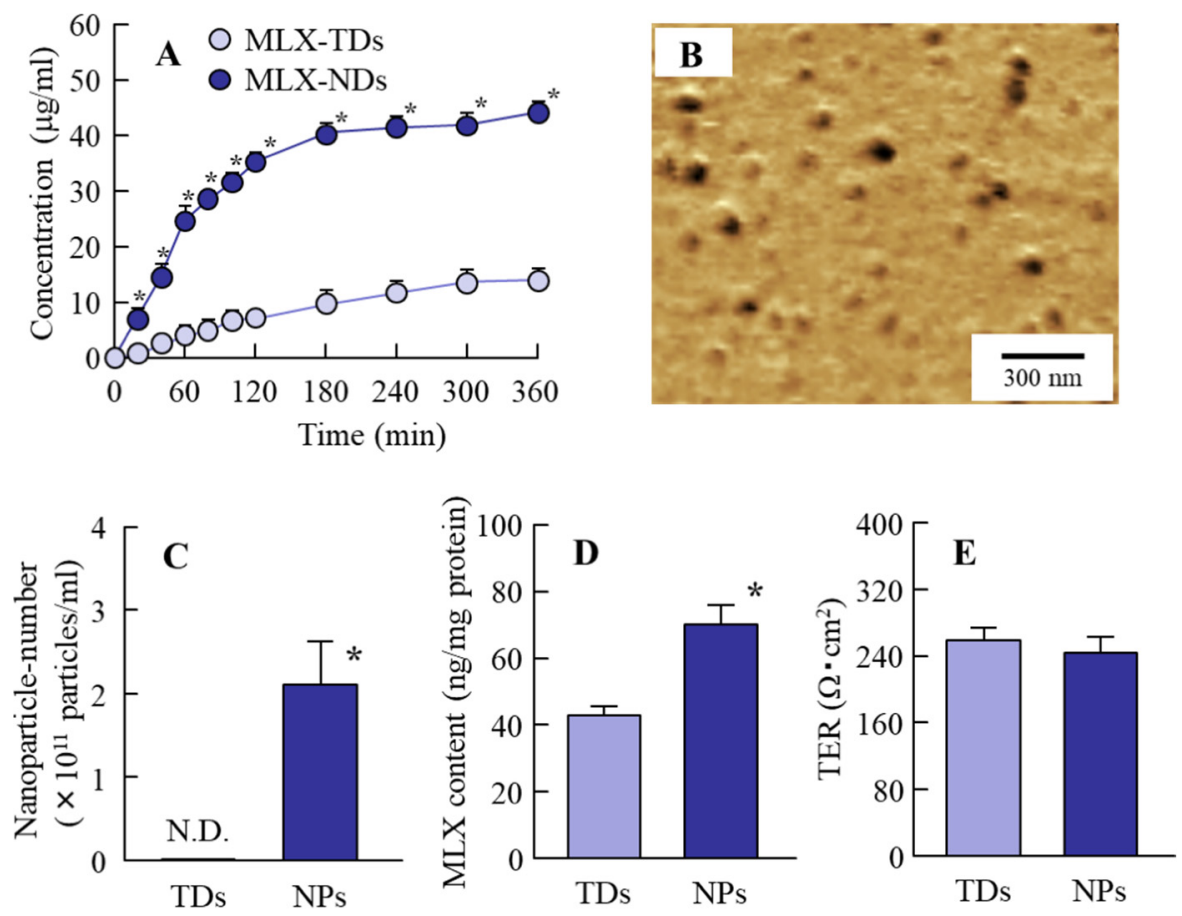

Figure 3. Trans-epithelial penetration of MLX from MLX-NPs $(0.2 \mathrm{mg} / \mathrm{mL})$ through Caco-2 cell monolayers. (A) Penetration of MLX formulations through Caco-2 cell monolayers. (B) AFM image of MLX-NPs on the basolateral side. (C) Number of nanoparticles from MLX-NPs on the basolateral side. (D) Accumulation of MLX in Caco-2 cells treated with MLX formulations. (E) TER of Caco-2 cell monolayers after treatment with MLX formulations. N.D., not-detected. $n=8 .{ }^{*} P<0.05$ vs. MLX-TDs for each category. The trans-epithelial penetration and intracellular uptake from MLX-NPs were significantly higher than that from MLX-TDs, and some MLX particles passed through the Caco-2 cell monolayers as nanoparticles. Cell toxicity was similar between MLX-TDs and MLX-NPs.

Next, we investigated the mechanism of the intestinal penetration of MLX nanoparticles using isolated rat intestine and various inhibitors of energy-dependent endocytosis (Figure 4).

High intestinal penetration was observed for MLX-NPs under normal conditions $\left(37^{\circ} \mathrm{C}\right)$, while intestinal penetration was prevented under low temperature $\left(4^{\circ} \mathrm{C}\right)$ conditions $(P<0.05$, Figure $4 \mathrm{~A}, \mathrm{~B})$, and the decrease of intestinal penetration in MLX-NPs under low-temperature $\left(4^{\circ} \mathrm{C}\right)$ conditions were higher than that in MLX solution and MLX-TDs (Figure S4). It is known that energy-dependent uptake is inhibited under low-temperature conditions [36], thus energy-dependent uptake may be related to the intestinal penetration of MLX-NPs. Endocytosis is one form of energy-dependent uptake and has been reported to be involved in the uptake of nanoparticles into cells [18,21]. Therefore, we investigated MLX penetration of the jejunum and ileum in the presence of various endocytosis inhibitors. Endocytosis is mainly classified as CavME, CME, MP, and phagocytosis, which are inhibited by nystatin, dynasore, rottlerin, and cytochalasin D, respectively [22-24]. Nystatin binds to plasma membrane cholesterol, and dynasore blocks dynamin. Rottlerin inhibits fluid-phase endocytosis, and cytochalasin D prevents the disassembly and actin polymerization of the actin cytoskeleton. These actions cause the inhibition of each type of endocytosis and are used as selective inhibitors of endocytosis [22-24]. In both the jejunum and ileum, treatment with nystatin, dynasore, and rottlerin significantly inhibited the intestinal penetration of $\operatorname{MLX}(P<0.05$, Figure $4 \mathrm{C}-\mathrm{F})$. These results indicate that three endocytosis pathways (CavME, CME, and MP) are related to the uptake of MLX solid nanoparticles (Scheme 1). On the other hand, in contrast to the results with Caco-2 cell monolayers, no MLX nanoparticles were detected on the basolateral side of the jejunum and ileum. Therefore, it is hypothesized that the absorbed MLX solid nanoparticles are dissolved in the small intestine, and pass into the blood in the dissolved form (Scheme 1). 

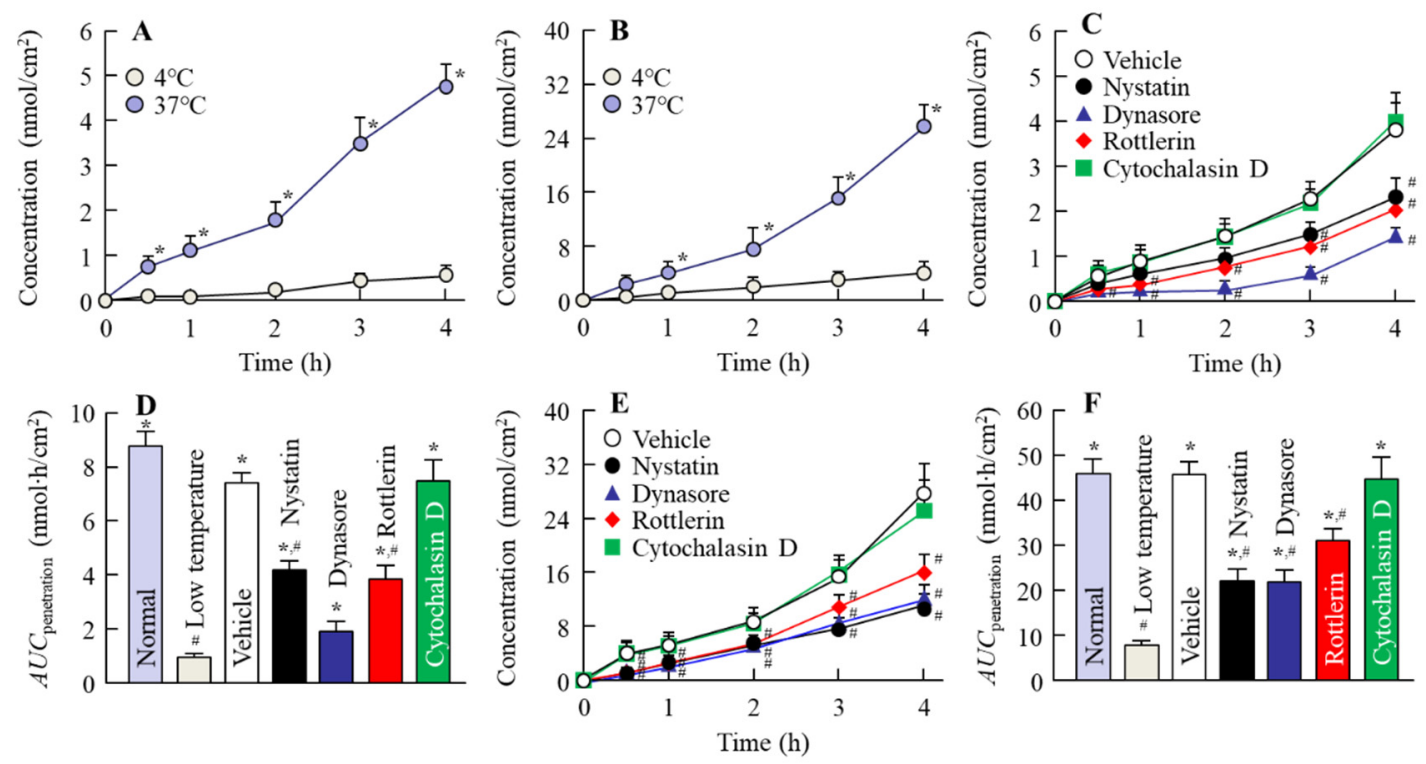

Figure 4. Effect of energy-dependent endocytosis on the intestinal penetration of MLX-NPs $(0.2 \mathrm{mg} / \mathrm{mL})$. $(\mathbf{A}, \mathbf{B})$ Intestinal penetration of MLX through the jejunum (A) and ileum (B) treated with MLX-NPs at $4{ }^{\circ} \mathrm{C}$ and $37^{\circ} \mathrm{C}$ conditions. (C,D), changes in intestinal penetration profile (C) and $A U C_{\text {penetration }}(\mathbf{D})$ of MLX-NPs in the jejunum applied at low temperature or at normal temperature in the presence of various endocytosis inhibitors. $(\mathbf{E}, \mathbf{F})$, changes in intestinal penetration profile $(\mathbf{E})$ and $A U C_{\text {penetration }}$ (F) of MLX-NPs in the ileum applied at low temperature or at normal temperature in the presence of various endocytosis inhibitors. $n=6-8 .{ }^{*} \mathrm{P}<0.05$ vs. $4{ }^{\circ} \mathrm{C}$ (low temperature) for each category. ${ }^{\#} P<0.05$ vs. Vehicle for each category. The intestinal penetration of MLX-NPs was remarkably suppressed under low-temperature conditions, and at normal temperature by treatment with nystatin, dynasore or rottlerin.

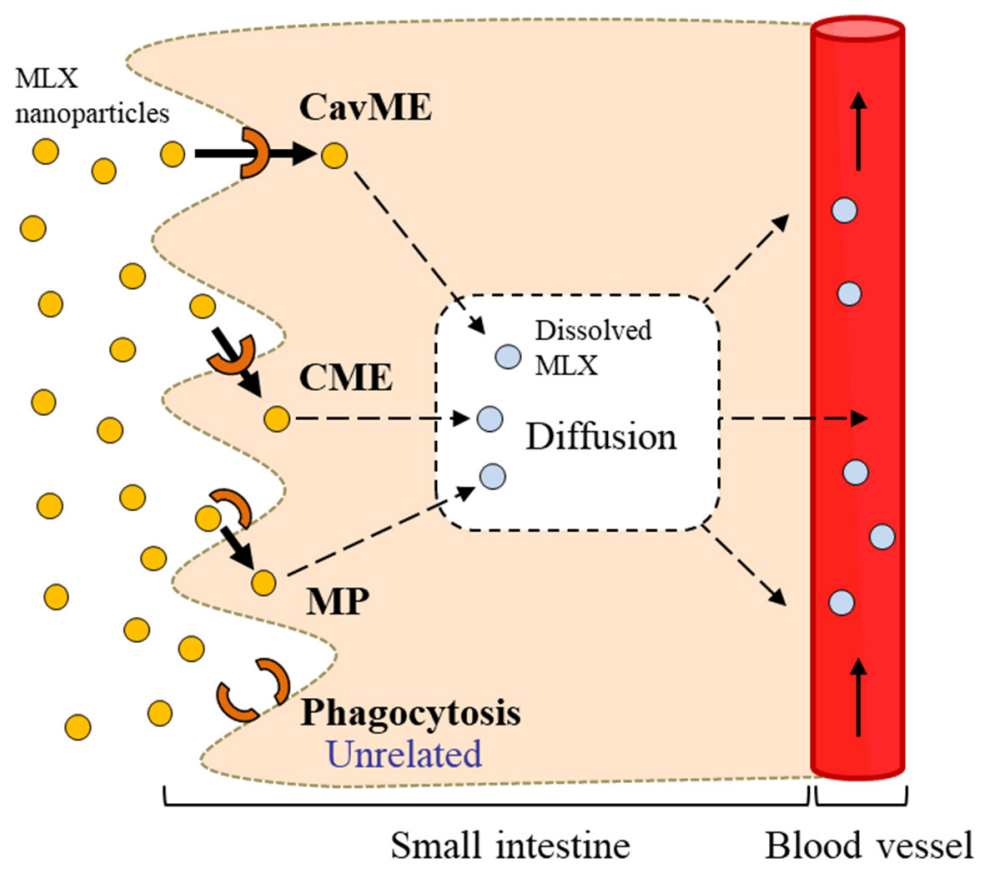

Scheme 1. Schematic illustration of the intestinal absorption of MLX-NPs via energy-dependent endocytosis pathways. Three endocytosis pathways (CavME, CME, and MP) are related to the uptake of MLX nanoparticles. The absorbed MLX nanoparticles are dissolved in the small intestine and pass through into the blood. 


\subsection{Usefulness of Oral Formulations of MLX Solid Nanoparticles as Therapy for RA Patients}

It is important to evaluate the safety of MLX solid nanoparticles for application in orally-administered formulations. First, we compared the MLX absorption profiles of MLX-NPs and MLX-TDs. The intestinal penetration for MLX-NPs was significantly higher than for MLX-TDs $(P<0.05$, Figure 5A), and the peak plasma concentration was reached in approximately $1.4 \mathrm{~h}$ following the application of MXL-NPs (Table S1). Moreover, the apparent absorption rate constant $\left(k_{\mathrm{a}}\right)$ of MLX-NPs was 7.6-fold that of MLX-TDs $(P<0.05$, Table S1). Hanft et al. and Dellgado et al. reported that traditional oral suspensions of MLX reach a peak plasma concentration 3-7 h after application, which was far too long for a quick onset of effect $[5,6]$. The use of MLX-NPs may improve these problems since the $t_{\max }$ of MLX-NPs is shorter than that of MLX-TDs (Figure 5A). In addition, the intestinal retention of MLX-NPs is significantly prolonged in comparison with MLX-TDs in the stomach, jejunum, and ileum $(P<0.05$, Figure 5D-F). The enhanced solubility (Figure $1 \mathrm{~F})$, penetration via endocytosis (Scheme 1), and intestinal drug retention (Figure 5D-F) may result in an increase of MLX absorption from MLX-NPs (Figure 5A).
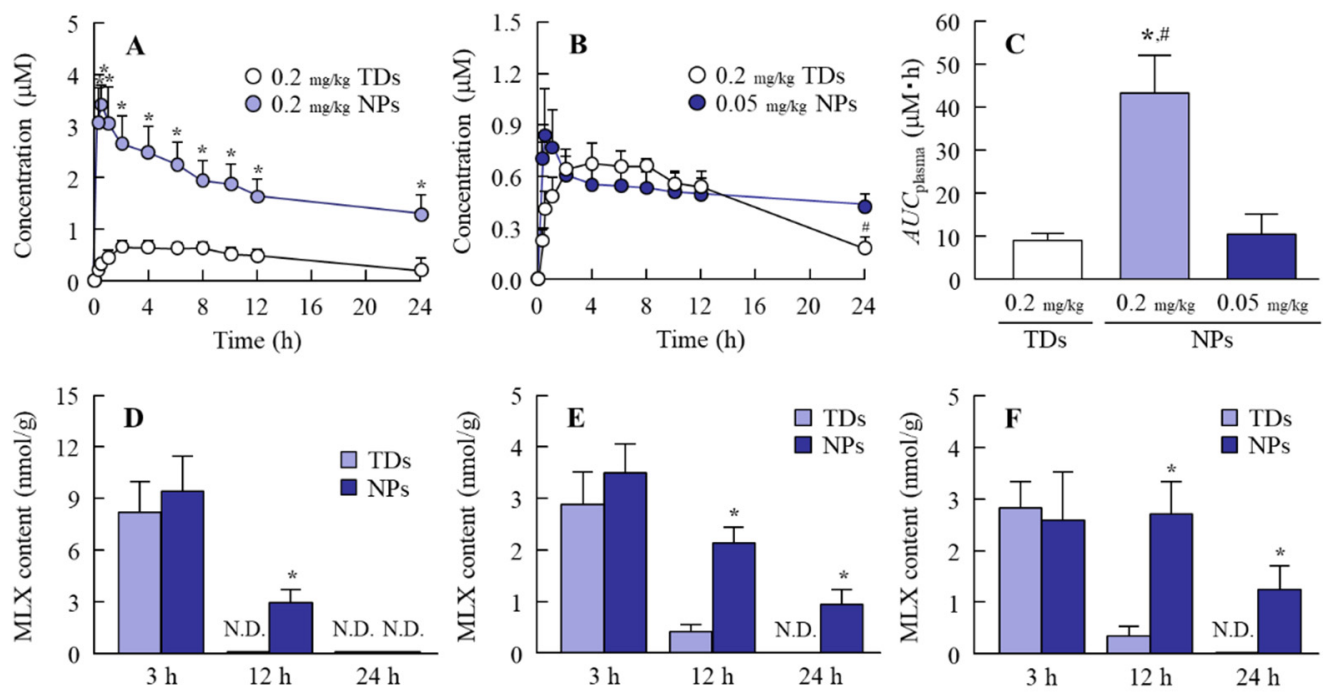

Figure 5. Differences in the MLX absorption profiles in rats orally administered MLX-TDs or MLX-NPs. (A) MLX absorption profile in rats orally administered $0.2 \mathrm{mg} / \mathrm{kg}$ MLX-TDs and $0.2 \mathrm{mg} / \mathrm{kg}$ MLX-NPs. (B) MLX absorption profile in rats orally administered $0.2 \mathrm{mg} / \mathrm{kg}$ MLX-TDs or $0.05 \mathrm{mg} / \mathrm{kg}$ MLX-NPs. (C) $A U C_{\text {plasma }}$ in rats orally administered $0.2 \mathrm{mg} / \mathrm{kg}$ MLX-TDs or $0.05 \mathrm{mg} / \mathrm{kg}$ or $0.2 \mathrm{mg} / \mathrm{kg}$ MLX-NPs. (D-F) Amount of MLX in the stomach (D), jejunum (E), and ileum (F) of rats orally administered $0.2 \mathrm{mg} / \mathrm{kg}$ MLX-TDs or MLX-NPs. N.D., not-detected. $n=6-10 .{ }^{*} P<0.05 \mathrm{vs} .0 .2 \mathrm{mg} / \mathrm{kg}$ MLX-TDs for each category. ${ }^{\#} P<0.05$ vs. $0.2 \mathrm{mg} / \mathrm{kg}$ MLX-NPs for each category. The $t_{\max }$ for MLX-NPs was shorter in comparison with MLX-TDs, and the peak plasma concentration was reached in approximately $1.4 \mathrm{~h}$ following the administration of MXL-NPs. The ratio of absorption in MLX-NPs was 5-fold higher than in MLX-TDs, and the $A U C_{\text {plasma }}$ was similar between of $0.2 \mathrm{mg} / \mathrm{kg}$ MLX-TDs and $0.05 \mathrm{mg} / \mathrm{kg}$ MLX-NPs. In addition, the intestinal retention with MLX-NPs was significantly prolonged in comparison with MLX-TDs in the stomach, jejunum, and ileum.

The plasma drug concentration reflects drug efficacy in therapy. Therefore, we attempted to obtain the same $A U C_{\text {plasma }}$ between of MLX-TDs and MLX-NPs by measuring the plasma MLX concentration in rats receiving $0.2 \mathrm{mg} / \mathrm{kg}$ MLX-TDs or $0.05 \mathrm{mg} / \mathrm{kg}$ MLX-NPs, since the absolute BA in the MLX-MPs and MLX-NPs were $20.3 \pm 4.9 \%$ and $91.9 \pm 8.9 \%$, respectively, and the $A U C_{\text {plasma }}$ for MLX-NPs was approximately 5-fold that of MLX-NPs in Figure 5A. Consistent with this, the $A U C_{\text {plasma values were }}$ similar between $0.2 \mathrm{mg} / \mathrm{kg}$ MLX-TDs and $0.05 \mathrm{mg} / \mathrm{kg}$ MLX-NPs (Figure 5B and C). Next, the therapeutic effect on inflammation was measured in AA rats (Figure 6). The therapeutic effect of MLX-NPs was significantly higher than that of MLX-TDs at the corresponding dose $(P<0.05)$, and the therapeutic 
effect ( $A U C_{\text {edema }}$ ) was similar between $0.2 \mathrm{mg} / \mathrm{kg}$ MLX-TDs and $0.05 \mathrm{mg} / \mathrm{kg}$ MLX-NPs. These results supported the data in Figure 5A, which is that the ratio of absorption for MLX-NPs is 5-fold higher than that for MLX-TDs.
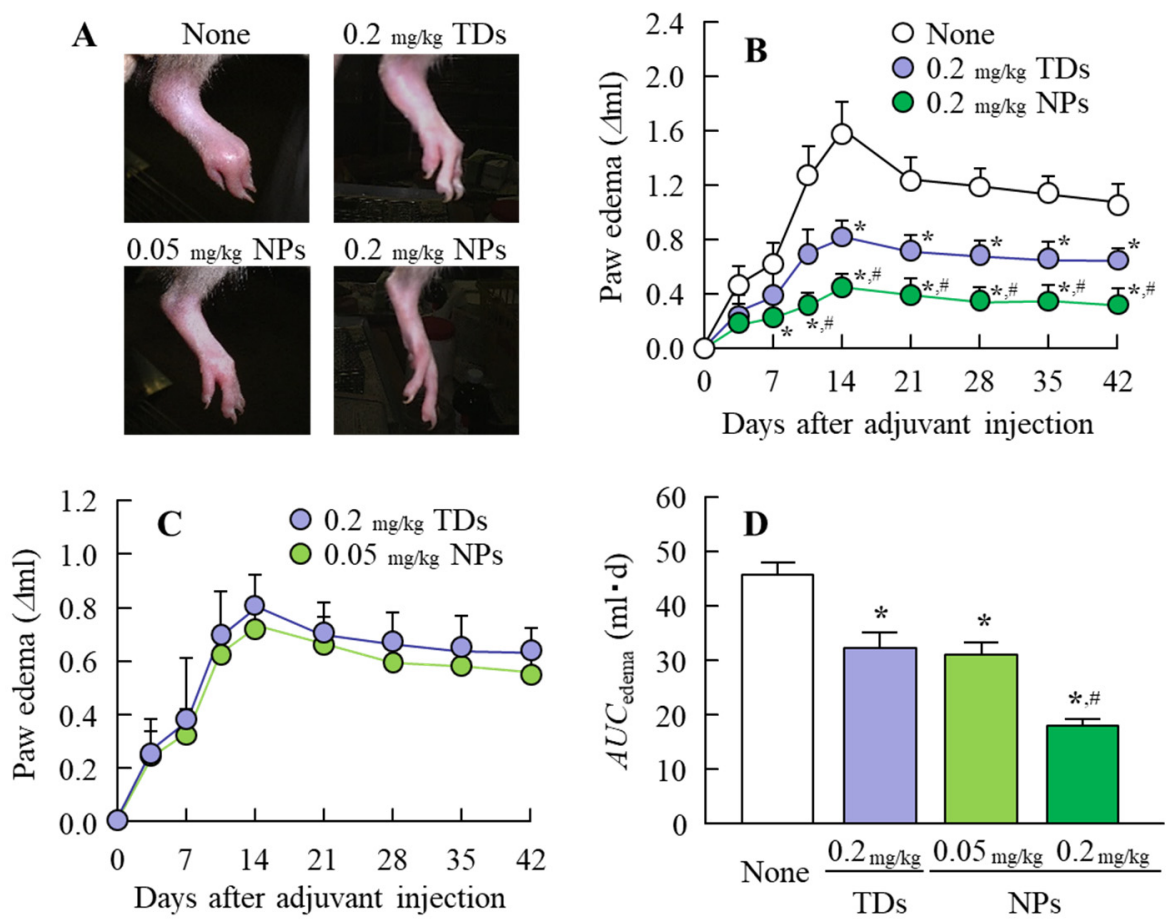

Figure 6. The therapeutic effect of MLX-NPs in AA rats. (A) Image of paw edema of AA rats orally administered MLX formulations. (B) Changes in paw edema of rats orally administered $0.2 \mathrm{mg} / \mathrm{kg}$ MLX-TDs or MLX-NPs. (C) Changes in paw edema of AA rats orally administered $0.2 \mathrm{mg} / \mathrm{kg}$ MLX-TDs or $0.05 \mathrm{mg} / \mathrm{kg}$ MLX-NPs. (D) $A U C_{\text {edema }}$ of AA rats orally administered $0.2 \mathrm{mg} / \mathrm{kg}$ MLX-TDs or $0.05 \mathrm{mg} / \mathrm{kg}$ or $0.2 \mathrm{mg} / \mathrm{kg}$ MLX-NPs. $n=8 .{ }^{*} P<0.05$ vs. None for each category. ${ }^{\#} P<0.05 \mathrm{vs} .0 .2 \mathrm{mg} / \mathrm{kg}$ MLX-TDs for each category. The therapeutic effect of MLX-NPs was significantly higher than that of MLX-TDs at the corresponding dose, and the $A U C_{\text {edema }}$ was similar between $0.2 \mathrm{mg} / \mathrm{kg}$ MLX-TDs and $0.05 \mathrm{mg} / \mathrm{kg}$ MLX-NPs.

The gastrointestinal ulcerogenic response is a known side effect of NSAIDs, and RA patients taking NSAIDs are more susceptible to NSAIDs induced gastric and small intestinal ulcerogenic lesions than other patients [37,38]. In this study, AA rats were used as the model of RA to investigate the side effects of MLX-TDs and MLX-NPs at corresponding $A U C_{\text {plasma }}$ levels. Figure 7 shows the gastrointestinal lesions in AA rats after the repetitive administration of $0.2 \mathrm{mg} / \mathrm{kg}$ MLX-TDs or $0.05 \mathrm{mg} / \mathrm{kg}$ MLX-NPs for 1 month. Gastrointestinal lesions were observed following the repetitive oral administration of MLX-TDs. On the other hand, no intestinal lesions were detected in the rats treated with MLX-NPs, and there were fewer gastric lesions in rats treated with MLX-NPs than in rats administered MLX-TDs $(P<0.05)$. Previous studies have reported that NSAIDs inhibit cyclooxygenase and cause the depletion of endogenous prostaglandins (PG), resulting in the formation of gastric lesions [39-41]. In addition, the direct stimulation by NSAIDs in the stomach and small intestine induces the overexpression of neutrophils, the formation of nitric oxide (NO) via inducible NO synthase, and these changes in the levels of neutrophils, NO and prostaglandins cause the pathogenesis of intestinal ulceration [39-41]. Taken together, the data suggest decreasing the MLX dosage (the amount administered orally) by improving BA attenuates the direct stimulation by MLX in the stomach and small intestine, resulting in a decrease in the onset of gastrointestinal lesions. Further studies are needed to clarify the changes in neutrophils, NO, and prostaglandins in the stomach and small intestine of rats treated with MLX solid nanoparticles. The present results suggest that treatment with low doses of MLX-NPs may enable 
RA therapy without intestinal ulcerogenic responses to NSAIDs. On the other hand, the rat model is different from humans, since the BA of MLX is higher than that in the rat model [7]. Further study is needed in RA patients.

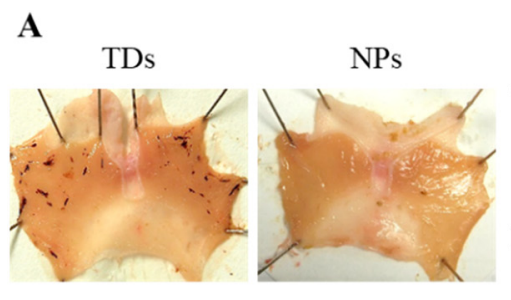

B

TDs

NPs

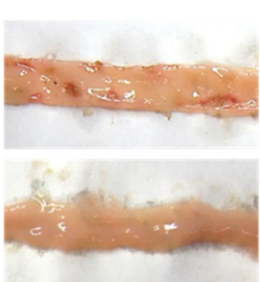

C

TDs

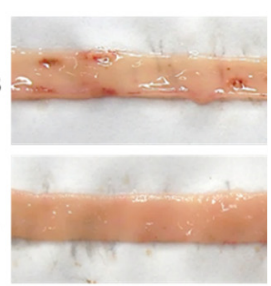

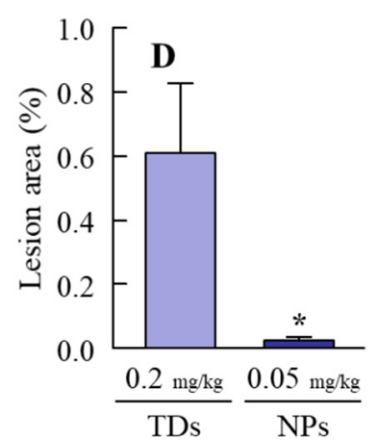
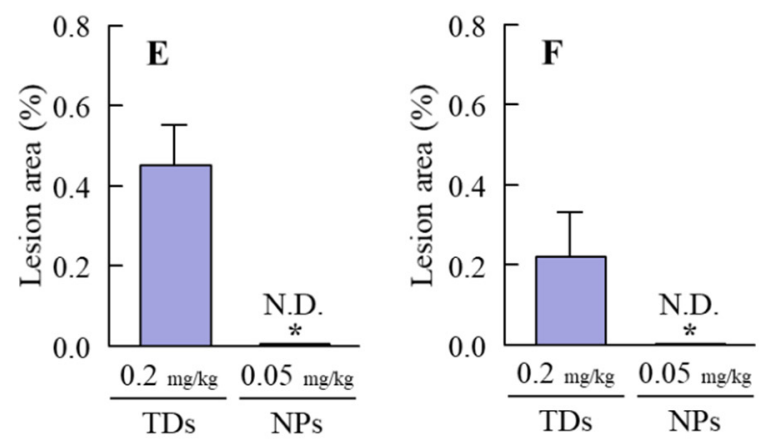

Figure 7. Onset of gastrointestinal lesions by the repetitive administration of $0.2 \mathrm{mg} / \mathrm{kg}$ MLX-TDs or $0.05 \mathrm{mg} / \mathrm{kg}$ MLX-NPs. (A-C) Images of the stomach (A), jejunum (B), and ileum (C) of AA rats following the repetitive oral administration of MLX formulations. (D-F) Lesion areas of the stomach (D), jejunum (E), and ileum (F) of AA rats following the repetitive oral administration of MLX formulations. N.D., not-detected. $n=8 .{ }^{*} P<0.05$ vs. MLX-TDs for each category. Gastrointestinal lesions were observed following the repetitive oral administration of MLX-TDs. On the other hand, no intestinal lesions were detected in rats following the repetitive oral administration of $0.05 \mathrm{mg} / \mathrm{kg}$ MLX-NPs, and the number of gastric lesions in rats treated with $0.05 \mathrm{mg} / \mathrm{kg}$ MLX-NPs was less than that of rats treated with $0.2 \mathrm{mg} / \mathrm{kg}$ MLX-TDs.

\section{Conclusions}

We designed formulations of MLX solid nanoparticles for oral administration. These MLX formulations show high rates of intestinal absorption and retention and enable a quick onset of the therapeutic effect. Moreover, we demonstrated that three energy-dependent endocytosis pathways (CavME, CME, and MP) are related to the high rate of intestinal penetration of MLX solid nanoparticles. In addition, we found that MLX solid nanoparticles make it possible to decrease the amount of MLX administered due to the improved BA, and that treatment with low doses of MLX-NPs enable RA therapy without the intestinal ulcerogenic responses to NSAIDs (Scheme 2). These findings are useful in studies to design therapies for RA patients. 


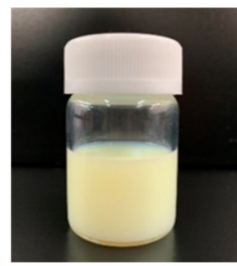

Nanomedicine

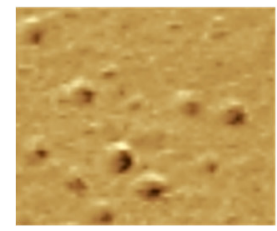

O

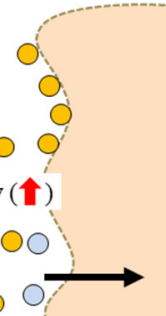

Solubility (수)

PO, Absorption (수

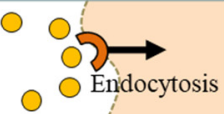

(3) Penetration (1)

Dissolved MLX

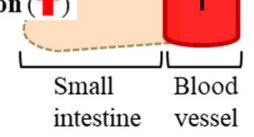

Merit 1 Dosage (

$\rightarrow$ Gastrointestinal disorders $(\forall)$

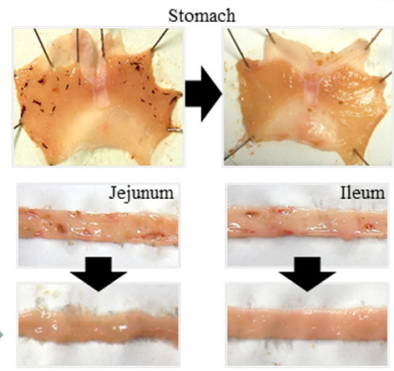

Merit $2 t_{\max }(\boldsymbol{I}), \mathbf{B A}$ (수

$\rightarrow$ Therapeutic effect (1)

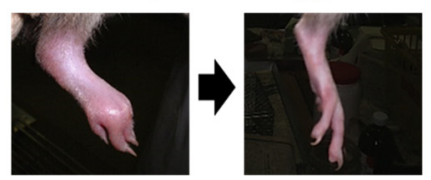

Scheme 2. Schematic illustration of the absorption mechanism and usefulness of orally administrated MLX-NPs.

Supplementary Materials: The following are available online at http://www.mdpi.com/1999-4923/12/4/313/s1, Figure S1. Characteristics of MLX treated with or without the bead mill. (A) and (B), particle frequency of MLX-TDs (A), and MLX-NPs (B) by SALD-7100. Figure S2. XRD pattern of MLX with (B) or without (A) bead mill treatment. Figure S3. In vitro trans-epithelial penetration study using Caco-2 cell monolayers. (A) The effect of culture time on TER values of Caco-2 cell monolayers. (B) Particle frequency of MLX-NPs on the basolateral side. Figure S4. Intestinal penetration of MLX solution and MLX-TDs in the rats. (A) and (B), intestinal penetration of MLX through the jejunum (A) and ileum (B) treated with MLX solution at $4{ }^{\circ} \mathrm{C}$ and $37^{\circ} \mathrm{C}$ conditions. (C) and (D), intestinal penetration of MLX through the jejunum (C) and ileum (D) treated with MLX-TDs at $4{ }^{\circ} \mathrm{C}$ and $37^{\circ} \mathrm{C}$ conditions. Table S1. Pharmacokinetic analysis of the in vivo absorption of MLX formulations.

Author Contributions: Conceptualization, N.N; data curation, F.O. and H.O.; formal analysis, F.O., H.O., and N.K.; funding acquisition, N.N.; investigation, F.O. and H.O.; methodology, N.N., F.O., and N.K.; supervision, N.N. and N.K.; visualization, N.N.; writing—original draft, N.N.; writing-review and editing, N.N. All authors have read and agreed to the published version of the manuscript.

Funding: This work was supported in part by a grant, 18K06769, from the Ministry of Education, Culture, Sports, Science, and Technology of Japan.

Conflicts of Interest: The authors declare no conflict of interest.

\section{References}

1. Ambrus, R.; Kocbek, P.; Kristl, J.; Sibanc, R.; Rajko, R.; Szabo-Revesz, P. Investigation of preparation parameters to improve the dissolution of poorly water-soluble meloxicam. Int. J. Pharm. 2009, 381, 153-159. [CrossRef] [PubMed]

2. Monteiro, B.P.; Klinck, M.P.; Moreau, M.; Guillot, M.; Steagall, P.V.M.; Edge, D.K.; Pelletier, J.-P.; Martel-Pelletier, J.; Gauvin, D.; del Castillo, J.R.E.; et al. Analgesic efficacy of an oral transmucosal spray formulation of meloxicam alone or in combination with tramadol in cats with naturally occurring osteoarthritis. Vet. Anaesth. Analg. 2016, 43, 643-651. [CrossRef] [PubMed]

3. Khachane, P.; Date, A.A.; Nagarsenker, M.S. Positively charged polymeric nanoparticles: Application in improving therapeutic efficacy of meloxicam after oral administration. Die Pharm. 2011, 66, 334-338.

4. Goldman, A.P.; Williams, C.S.; Sheng, H.; Lamps, L.W.; Williams, V.P.; Pairet, M.; Morrow, J.D.; DuBois, R.N. Meloxicam inhibits the growth of colorectal cancer cells. Carcinogenesis 1998, 19, 2195-2199. [CrossRef]

5. Hanft, G.; Türck, D.; Scheuerer, S.; Sigmund, R. Meloxicam oral suspension: A treatment alternative to solid meloxicam formulations. Inflamm. Res. 2001, 50, S35-S37. [CrossRef] [PubMed]

6. Dellgado, D.R.; Jouyban, A.; Martinez, F. Solubility and preferential solvation of meloxicam in methanol + water mixtures at 298.15 K. J. Mol. Liq. 2014, 197, 368-373. [CrossRef] 
7. Del Tacca, M.; Colucci, R.; Fornai, M.; Blandizzi, C. Efficacy and tolerability of meloxicam, a COX-2 preferential nonsteroidal antiinflamatory drug: A review. Clin. Drug Investig. 2002, 22, 799-818. [CrossRef]

8. Turck, D.; Busch, U.; Heinzel, G.; Narjes, H. Clinical pharmacokinetics of meloxicam. Arzneimittelforschung 1997, 47, 253-258.

9. Hobbs, D.C. Piroxicam pharmacokinetics: Recent clinical results relating kinetics and plasma levels to age, sex, and adverse effects. Am. J. Med. 1986, 81, 22-28.

10. Nilsen, O.G. Clinical pharmacokinetics of tenoxicam. Clin. Pharmacokinet. 1994, 26, 16-43. [CrossRef]

11. Leuner, C.; Dressman, J. Improving drug solubility for oral delivery using solid dispersions. Eur. J. Pharm. Biopharm. 2000, 50, 47-60. [CrossRef]

12. He, C.X.; He, Z.G.; Gao, J.Q. Microemulsions as drug delivery systems to improve the solubility and the bioavailability of poorly water-soluble drugs. Expert Opin. Drug Deliv. 2010, 7, 445-460. [CrossRef] [PubMed]

13. Merisko-Liversidge, E.; Liversidge, G.G.; Cooper, E.R. Nanosizing: A formulation approach for poorly-water-soluble compounds. Eur. J. Pharm. Sci. 2003, 18, 113-120. [CrossRef]

14. Serajuddin, A.T.M. Salt formation to improve drug solubility. Adv. Drug Deliv. Rev. 2007, 59, $603-616$. [CrossRef] [PubMed]

15. Rabinow, B.E. Nanosuspension in drug delivery. Nat. Rev Drug Discov. 2004, 3, 785-796. [CrossRef]

16. Patravale, V.B.; Date, A.A.; Kulkarni, R.M. Nanosuspensions: A promising drug delivery strategy. J. Pharm. Pharmacol. 2004, 56, 827-840. [CrossRef]

17. Kesisoglon, F.; Panmai, S.; Wu, Y. Nanosizing oral formulation development and biopharmaceutical evaluation. Adv. Drug. Dev. Rev. 2007, 59, 631-644. [CrossRef]

18. Nagai, N.; Ogata, F.; Otake, H.; Nakazawa, Y.; Kawasaki, N. Energy-dependent endocytosis is responsible for drug transcorneal penetration following the instillation of ophthalmic formulations containing indomethacin nanoparticles. Int. J. Nanomed. 2019, 14, 1213-1227. [CrossRef]

19. Nagai, N.; Ogata, F.; Yamaguchi, M.; Fukuoka, Y.; Otake, H.; Nakazawa, Y.; Kawasaki, N. Combination with 1-Menthol Enhances Transdermal Penetration of Indomethacin Solid Nanoparticles. Int. J. Mol. Sci. 2019, 20, 3644. [CrossRef]

20. Nagai, N.; Iwamae, A.; Tanimoto, S.; Yoshioka, C.; Ito, Y. Pharmacokinetics and antiinflammatory effect of a novel gel system containing ketoprofen solid nanoparticles. Biol. Pharm. Bull. 2015, 38, 1918-1924. [CrossRef]

21. Ishii, M.; Fukuoka, Y.; Deguchi, S.; Otake, H.; Tanino, T.; Nagai, N. Energy-dependent endocytosis is involved in the absorption of indomethacin nanoparticles in the small intestine. Int. J. Mol. Sci. 2019, 20, 476. [CrossRef] [PubMed]

22. Mäger, I.; Langel, K.; Lehto, T.; Eiríksdóttir, E.; Langel, U. The role of endocytosis on the uptake kinetics of luciferin-conjugated cell-penetrating peptides. Biochim. Biophys. Acta 2012, 1818, 502-511. [CrossRef] [PubMed]

23. Malomouzh, A.I.; Mukhitov, A.R.; Proskurina, S.E.; Vyskocil, F.; Nikolsky, E.E. The effect of dynasore, a blocker of dynamin-dependent endocytosis, on spontaneous quantal and non-quantal release of acetylcholine in murine neuromuscular junctions. Dokl. Biol. Sci. 2014, 459, 330-333. [CrossRef] [PubMed]

24. Hufnagel, H.; Hakim, P.; Lima, A.; Hollfelder, F. Fluid phase endocytosis contributes to transfection of DNA by PEI-25. Mol. Ther. 2009, 17, 1411-1417. [CrossRef] [PubMed]

25. Gawde, K.A.; Kesharwani, P.; Sau, S.; Sarkar, F.H.; Padhye, S.; Kashaw, S.K.; Iyer, A.K. Synthesis and characterization of folate decorated albumin bio-conjugate nanoparticles loaded with a synthetic curcumin difluorinated analogue. J. Colloid Interface Sci. 2017, 496, 290-299. [CrossRef]

26. Kocbek, P.; Baumgartner, S.; Kristl, J. Preparation and evaluation of nanosuspensions for enhancing the dissolution of poorly soluble drugs. Int. J. Pharm. 2006, 312, 179-186. [CrossRef]

27. Müller, R.H.; Akkar, A. Encyclopedia of Nanoscience and Nanotechnology; American Scientific Publishers: California, CA, USA, 2004; pp. 624-638.

28. Moschwitzer, J.P. Drug nanocrystals in the commercial pharmaceutical development process. Int. J. Pharm. 2013, 453, 142-156. [CrossRef]

29. Quan, P.; Shi, K.; Piao, H.; Liang, N.; Xia, D.; Cui, F. A novel surface modified nitrendipine nanocrystals with enhancement of bioavailability and stability. Int. J. Pharm. 2012, 430, 366-371. [CrossRef]

30. Abdelwahed, W.; Degobert, G.; Stainmesse, S.; Fessi, H. Freeze-drying of nanoparticles: Formulation, process and storage considerations. Adv. Drug Deliv. Rev. 2006, 58, 1688-1713. [CrossRef] 
31. Gallardo, E.; Sarria, B.; Espartero, J.L.; Correa, J.A.G.; Bravo-Clemente, L.; Mateos, R. Evaluation of the bioavailability and metabolism of nitroderivatives of hydroxytyrosol using Caco-2 and HepG2 human cell models. J. Agric. Food Chem. 2016, 64, 2289-2297. [CrossRef]

32. Qiu, J.; Kitamura, Y.; Miyata, Y.; Tamaru, S.; Tanaka, K.; Tanaka, T.; Matsui, T. Transepithelial transport of theasinensins through Caco-2 cell monolayers and their absorption in Sprague-Dawley rats after oral administration. J. Agric. Food Chem. 2012, 60, 8036-8043. [CrossRef]

33. Hughson, E.J.; Cutler, D.F.; Hopkins, C.R. Basolateral secretion of kappa light chain in the polarized epithelial cell line, Caco-2. J. Cell Sci. 1989, 94, 327-332. [PubMed]

34. Grasset, E.; Pinto, M.; Dussaulx, E.; Zweibaum, A.; Desjeux, J.F. Epithelial properties of human colonic carcinoma cell line Caco-2: Electrical parameters. Am. J. Physiol. 1984, 247, 260-267. [CrossRef]

35. Finlay, B.B.; Falkow, S. Salmonella interactions with polarized human intestinal Caco-2 epithelial cells. J. Infect. Dis. 1990, 162, 1096-1106. [CrossRef] [PubMed]

36. He, Z.; Liu, K.; Manaloto, E.; Casey, A.; Cribaro, G.P.; Byrne, H.J.; Tian, F.; Barcia, C.; Conway, G.E.; Cullen, P.J.; et al. Cold atmospheric plasma induces ATP-dependent endocytosis of nanoparticles and synergistic U373MG cancer cell death. Sci. Rep. 2018, 8, 5298. [CrossRef] [PubMed]

37. Smalley, W.E.; Ray, W.A.; Daugherty, J.R.; Grin, M.R. Nonsteroidal anti-inflammatory drugs and the incidence of hospitalizations for peptic ulcer disease in elderly persons. Am. J. Epidemiol. 1995, 141, 539-545. [CrossRef] [PubMed]

38. Fries, J.F.; Williams, C.A.; Bloch, D.A.; Michel, B.A. Non-steroidal anti-inflammatory drug-associated gastropathy: Incidence and risk factor models. Am. J. Med. 1991, 91, 213-222. [CrossRef]

39. Kato, S.; Ohkawa, F.; Ito, Y.; Amagase, K.; Takeuchi, K. Role of endothelial nitric oxide synthase in aggravation of indomethacin-induced gastric damage in adjuvant arthritic rats. J. Physiol. Pharmacol. 2009, 60, 147-155.

40. Nagai, N.; Sakamoto, R.; Yamamoto, S.; Deguchi, S.; Otake, H.; Tanino, T. Solid nanocrystals of rebamipide promote recovery from indomethacin-induced gastrointestinal bleeding. Int. J. Mol. Sci. 2019, 20, 4990. [CrossRef]

41. Nagai, N.; Ito, Y. Effect of solid nanoparticle of indomethacin on therapy for rheumatoid arthritis in adjuvant-induced arthritis rat. Biol. Pharm. Bull. 2014, 37, 1109-1118. [CrossRef]

(C) 2020 by the authors. Licensee MDPI, Basel, Switzerland. This article is an open access article distributed under the terms and conditions of the Creative Commons Attribution (CC BY) license (http://creativecommons.org/licenses/by/4.0/). 